\title{
INFLUÊNCIA DE EMBALAGENS E TEMPERATURA NO ARMAZENAMENTO DE JABUTICABAS (Myrciaria jabuticaba (Vell) Berg) cv 'SABARÁ'1
}

\author{
Maria Amalia BRUNINI ${ }^{2 *}$, Antonio Luis de OLIVEIRA ${ }^{3}$, Cleyton Alberto Ramos SALANDINI ${ }^{3}$,
}

\author{
Flavio Rodrigo BAZZO ${ }^{3}$
}

\begin{abstract}
RESUMO
Foram avaliadas jabuticabas 'sabará' maduras, acondicionadas em bandejas de polietileno tereftalato, revestidas externamente com filme plástico de PVC, esticável e alto aderente, de 12 e 20 micras, e em bandejas de poliestireno expandido, revestidas externamente com filme plástico de PVC, esticável e alto aderente, de 12 e 20 micras. Cada bandeja recebeu 25 frutos. As bandejas foram armazenadas à temperatura de $11 \pm 1^{\circ} \mathrm{C}$ com $98 \%$ UR e em condições de ambiente (23,6 a 28,3 ${ }^{\circ} \mathrm{C}$ com 53,7 a $68,3 \%$ UR). Como controle utilizaram-se frutos acondicionados em bandejas de polietileno tereftalato $(12 \times 20 \times 5 \mathrm{~cm})$ não recobertas com filme plástico. Considerando-se os resultados obtidos pode-se concluir que o uso de embalagem associada à baixa temperatura reduziu a perda de massa fresca, prolongou a vida-útil dos frutos com manutenção da aparência até 6 dias, não influenciou na evolução dos teores de acidez total titulável, sólidos solúveis totais e pH, mas interferiu na evolução de carboidratos solúveis e vitamina C. Os frutos acondicionados não recobertos com filme plástico e armazenados em condições ambiente resistiram 2 dias, mas ao final não apresentaram aparência aceitável para comercialização, pois haviam emurchecido e enrugado. As condições de refrigeração $\left(11 \pm 1^{\circ} \mathrm{C}\right)$ melhoraram a resistência dos frutos acondicionados não recobertos com filmes plásticos, entretanto, após 4 dias apresentaram má aparência.

Palavras-chave: jabuticaba; vida-útil; embalagens; armazenamento; qualidade pós-colheita.
\end{abstract}

\section{SUMMARY}

PACKAGING AND TEMPERATURE INFLUENCES ON THE STORAGE OF JABOTICABA (Myrciaria jabuticaba (vell) Berg) FRUITS cv.'SABARÁ'. Were evaluated mature jaboticaba 'sabará' fruits packaged into polystyrene expanded trays covered with stretching and sticking PVC plastic film, with stretching thickness of 12 and $20 \mu \mathrm{m}$, and packaged into tereftalato polyethylene trays covered with stretching and sticking PVC plastic film, with thickness of 12 and $20 \mu \mathrm{m}$. Into each tray were placed 25 fruits. The trays were stored at $11 \pm 1^{\circ} \mathrm{C}$ with $98 \% \mathrm{UR}$ and at environmental conditions $\left(23,6^{\circ} \mathrm{C}\right.$ to $28,3^{\circ} \mathrm{C}$ with $53,7 \%$ to $\left.68,3 \% \mathrm{UR}\right)$. Jaboticaba fruits packaged into tereftalato polyethylene trays $(12 \times 20 \times 5 \mathrm{~cm})$ and not corvered with plastic film were used as controls. Taking into considerations the results obtained it is observed that of the use of packaging reduced the weight loss, prolonged the postharvest life of fruits with maintenance the appearance until 6 days,; didn't interfere, significantly, in the titrable acidity, total soluble solids and pH, but influenced the soluble carbohydrates and vitamin $\mathrm{C}$ content. The fruits packed and not recovered with plastic films stored at environmental conditions, resisted until 2 days, but at the end of storage their aspect was not appropriate for market purpose, because showed shrinvelling skin and wither. The refrigeration condition improving the firmness of packaged fruits not covered with plastic film, however after 4 days showed bad appearance, with shrinvelling skin.

Keywords: jaboticaba fruits; packaging; postharvest quality; storage; shelf life.

\section{1 - INTRODUÇÃO}

A jabuticaba é nativa do Brasil, originária do CentroSul, podendo ser encontrada desde o Estado do Para até o Rio Grande do Sul, mas é nos Estados de São Paulo, Rio de Janeiro, Minas Gerais e Espírito Santo que ocorrem maiores produções. Dentre as espécies atualmente conhecidas, destaca-se a Myrciaria cauliflora (DC) Berg (jabuticaba paulista ou jabuticaba ponhem ou jabuticaba assú) e a Myrciaria jabuticaba (Vell) Berg (jabuticaba sabará) que produzem frutos apropriados tanto para a indústria como para consumo in natura $[8,20]$.

1. Recebido para publicação em 12/12/2002. Aceito para publicação em 09/06/2004 (001034). Pesquisa integrante do projeto: "Conservação pós-colheita de jabuticabas empregando-se embalagem, irradiação e cera em associação ao armazenamento refrigerado", financiado pela FAPESP (Proc. $n^{\circ}$ 01/00711-7).

2. Faculdade de Ciências Agrárias e Veterinárias 'Campus' de Jaboticabal/ UNESP e Faculdade "Dr. Francisco Maeda" da Fundação Educacional de Ituverava. Rodovia Jerônimo Nunes Macedo, Km 01, CEP: 14500000, Ituverava-SP; E-mail: amaliabrunini@netsite.com.br

3. Faculdade "Dr. Francisco Maeda" da Fundação Educacional de Ituverava. Rodovia Jerônimo Nunes Macedo, Km 01, CEP: 14500-000, ItuveravaSP. E-mail: toca@netsite.com.br

* A quem a correspondência deve ser enviada.
A jabuticabeira 'sabará' ocupa a maior área plantada entre as variedades brasileiras, apresenta frutos classificados como bacilo globoso, com 20 a 30mm de diâmetro, polpa macia, esbranquiçada e suculenta de sabor sub-ácido que tem embebida de uma a quatro sementes. Segundo DONADIO [8], a quantidade de jabuticabas comercializadas no CEAGESP no ano de 1989 foi de $921.524 \mathrm{~kg}$, passando em 1998 para $4.142 .047 \mathrm{~kg}$, portanto 4,5 vezes mais.

A jabuticabeira é uma das frutíferas que tem despertado grande interesse entre os produtores rurais devido a sua alta produtividade, rusticidade e aproveitamento de seus frutos nas mais diversas formas. É uma fruta tipicamente brasileira, que apesar de ser considerada apropriada tanto para consumo in natura como para a indústria $[9,19]$ tem seu comércio limitado devido a sua alta perecibilidade, que não somente reduz a quantidade produzida como também compromete a qualidade, principalmente o aspecto externo. Dentre os fatores que comprometem a qualidade dos frutos podese citar a perda de água, que resulta em murchamento, enrugamento da casca e perda de peso [2, 6], fatores estes importantes na comercialização.

Como outras frutas tropicais, a jabuticaba apresenta curto período de comercialização após a colhei- 
ta [10], conseqüentemente, são necessários estudos sobre técnicas de conservação visando estender sua vida útil sem afetar a qualidade. Dentre estas técnicas pós-colheita, pode-se citar o uso de armazenamento refrigerado e embalagens [2, 6, 7]. O uso de refrigeração, quando bem aplicado, é um dos meios mais eficaz na manutenção da qualidade e extensão do período de comercialização dos produtos hortifrutícolas, cuja função é retardar os processos metabólicos, porém sem ocasionar distúrbios fisiológicos, e prolongar o tempo de comercialização [2, 6, 16, 22, 23]. DUARTE, LUDDERS \& HUETE [10] citam que a melhor temperatura de armazenamento para frutas de jabuticabeiras é $12^{\circ} \mathrm{C}$, pois pode manter a qualidade dos frutos e estender a vida-útil.

O uso de embalagem pode reduzir a perda de massa fresca, as mudanças na aparência durante o armazenamento [17], aumentar de 50 a $400 \%$ a vida-útil dos frutos, reduzir as perdas econômicas e facilitar a distribuição dos produtos a longas distâncias sem comprometer a qualidade [12]. Para jabuticabas, a literatura especializada, praticamente, não disponibiliza informações relativas sobre conservação pós-colheita. Assim, o objetivo deste trabalho é o de avaliar o efeito de embalagens na qualidade pós-colheita e vida-útil de jabuticabas 'sabará' durante o armazenamento à baixa temperatura ou à temperatura ambiente, visando prolongar seu período de armazenamento.

\section{2 - MATERIAL E MÉTODOS}

Jabuticabas 'sabará' foram colhidas no estádio maduro, em pomar comercial na região de Casa BrancaSP, transportadas rapidamente para o Laboratório de Fruticultura da Faculdade "Dr. Francisco Maeda"FAFRAM/FE-Ituverava-SP, onde foram selecionadas visualmente, buscando uniformizar os lotes, quanto ao tamanho e descarte das frutas com lesões.

Os frutos foram divididos em cinco lotes, com aproximadamente $8 \mathrm{~kg}$ cada um, que foram, respectivamente, submetidos aos seguintes tratamentos: frutos acondicionados em bandejas de polietileno tereftalato $(12 \times 20 \times 5 \mathrm{~cm})$ não revestidas com filmes plásticos, que correspondeu ao grupo controle (SE); frutos acondicionados em bandejas de polietileno tereftalato, $5 \times 11 \times 14 \mathrm{~cm}$ de dimensões internas, revestidas externamente com filme plástico de PVC esticável e autoaderente, com 12 micras de espessura (BP1); frutos acondicionados em bandejas de polietileno tereftalato, de $5 \times 11 \times 14 \mathrm{~cm}$ de dimensões internas, revestidas externamente com filme plástico de PVC esticável e autoaderente, com 20 micras de espessura (BP2); frutos acondicionados em bandejas de poliestireno expandido, revestidas externamente com filme plástico de PVC, esticável e autoaderente, com 12 micras de espessura (BI1); e frutos acondicionados em bandejas de poliestireno expandido, revestidas externamente com filme plástico de PVC, esticável e autoaderente, com 20 micras de espessura (BI2). Os frutos foram colocados, em grupo de 25, em cada embalagem. Cada embalagem, em cada tratamento correspondeu a uma unidade experimental. As unidades experimentais de cada tratamento foram divididas em dois grupos, respectivamente, armazenados à temperatura de $11 \pm 1^{\circ} \mathrm{C}$ com 98\%UR em câmara fria, e em condições ambiente $\left(26,5\right.$ a $28,3^{\circ} \mathrm{C}, 53,7$ a $68,3 \%$ UR).

A eficiência dos tratamentos e a qualidade dos frutos foram determinados através dos parâmetros: perda de massa fresca pelos frutos, aparência, textura, coloração, acidez total titulável, $\mathrm{pH}$, sólidos solúveis totais, vitamina $\mathrm{C}$ e carboidratos solúveis. A perda de massa fresca foi determinada através da diferença entre a massa fresca inicial das unidades experimentais e a massa no dia da amostragem, e transformada em porcentagem. A aparência foi determinada, subjetivamente, através de exame visual, por 15 avaliadores treinados, utilizando-se uma escala de notas, onde: 1= ótima; 2 = boa; $3=$ razoável e $4=$ ruim/péssima (sem condições de comercialização), e a textura dos frutos, determinada também subjetivamente, por meio de uma leve pressão pela boca, por quinze provadores treinados, que atribuíram notas, utilizando-se também de uma escala, onde: $1=$ dura; $2=$ firme; $3=$ mole e $4=$ muito mole. A coloração da casca foi determinada segundo o sistema CILAB $\left(\mathrm{a}^{*} \mathrm{~b} * \mathrm{~L}\right)$, utilizando-se do refratômetro Minolta Chroma Meter CR-10, que a expressa em valores de 'L', a e b, que permitem calcular o 'Hue' [4].

A acidez total titulável (ATT), expressa em gramas de ácido cítrico por $100 \mathrm{~g}$ de polpa, e o teor de vitamina $\mathrm{C}$, expresso em mg de ácido ascórbico por $100 \mathrm{~g}$ de polpa foram determinados por titulometria de acordo com as normas do I.A.L. [14]. Os teores de sólidos solúveis totais (SST), expressos em ${ }^{\circ}$ Brix, foram determinados por refratometria, o $\mathrm{pH}$, expresso em unidades, e a relação SST/ATT conforme recomendação da AOAC[1] e TRESSLER \& JOSLYN [21]. Os teores de carboidratos solúveis, expressos em g de glicose por $100 \mathrm{~g}$ de polpa, foram quantificados pelo método do fenol-sulfúrico [11].

O delineamento experimental utilizado foi inteiramente casualizado, e as médias obtidas em cada tratamento foram comparadas com o valor inicial através do teste de Tukey, ao nivel de 5\% de probabilidade [3].

\section{3 - RESULTADOS E DISCUSSÃO}

A perda de massa fresca é uma das características que interfere na aceitabilidade do produto pelo consumidor. Os dados da Tabela 1 permitem verificar que ao final do período de armazenamento, os frutos acondicionados e não revestidos com filmes plásticos foram os que apresentaram a maior perda de massa fresca $(3,05 \%$ e $11,25 \%$ ), respectivamente, durante o armazenamento à baixa temperatura e em condições ambiente. Comparando-se a perda de massa fresca, em um mesmo período de armazenamento, 2 dias, observa-se que os frutos armazenados em condições ambiente tiveram maior perda de massa fresca, comportamento este coerente com o verificado por ZAMBRANO, BRICEÑO \& MENDES [24] e JERONIMO \& KANESIRO [15] em mangas. 
TABELA 1. Perda de massa fresca, expressa em porcentagem, de jabuticabas 'sabará', durante o armazenamento a baixa temperatura e em condições ambiente. Safra 2001 (Média de 5 repetições)

\begin{tabular}{|c|c|c|c|c|c|c|}
\hline \multirow{3}{*}{ Tratamentos } & \multicolumn{6}{|c|}{ Tempo de armazenamento em dias } \\
\hline & \multicolumn{3}{|c|}{ Em condições ambiente } & \multicolumn{3}{|c|}{ Sob refrigeração } \\
\hline & 0 & 2 & 3 & 2 & 4 & 6 \\
\hline $\begin{array}{l}\text { Bandejas de polietileno } \\
\text { tereftalato sem revestimento }\end{array}$ & $5,86 \mathrm{aB}$ & $11,25 \mathrm{aA}$ & & $1,20 \mathrm{aB}$ & $3,05 \mathrm{aA}$ & \\
\hline $\begin{array}{l}\text { Bandejas de polietileno } \\
\text { tereftalato, revestidas com: }\end{array}$ & & & & & & \\
\hline -filme de $12 \mu \mathrm{m}$ (BP1) & $0,76 \mathrm{cC}$ & $1,53 \mathrm{cB}$ & $2,31 \mathrm{bA}$ & $0,15 \mathrm{cC}$ & $0,23 b B$ & $0,38 a b A$ \\
\hline -filme de $20 \mu \mathrm{m}$ (BP2) & $0,73 c C$ & $1,45 \mathrm{cB}$ & $2,17 \mathrm{aA}$ & $0,16 \mathrm{cC}$ & $0,27 \mathrm{bB}$ & $0,43 a A$ \\
\hline $\begin{array}{l}\text { Bandejas de poliestireno } \\
\text { expandido, revestidas com: }\end{array}$ & & & & & & \\
\hline -filme de $12 \mu \mathrm{m}$ (Bl1) & $1,08 \mathrm{cC}$ & $2,11 \mathrm{bcB}$ & $3,14 \mathrm{cA}$ & $0,14 \mathrm{cC}$ & $0,23 b B$ & $0,44 \mathrm{bA}$ \\
\hline -filme de $20 \mu \mathrm{m}(\mathrm{Bl} 2)$ & $0,71 b \mathrm{~b}$ & $1,56 \mathrm{bB}$ & $2,41 \mathrm{cA}$ & $0,21 \mathrm{bC}$ & $0,34 \mathrm{bB}$ & $0,51 a b A$ \\
\hline c.v. (1) & 6,68 & 13,82 & 4,82 & 9,43 & 13,50 & 14,85 \\
\hline m.g. ${ }^{(1)}$ & 1,94 & 3,76 & 2,83 & 0,37 & 0,82 & 0,4390 \\
\hline
\end{tabular}

(1) $\mathrm{cv}=$ coeficiente de variação em porcentagem; m.g.= media geral. Médias seguidas pela mesma letra, nas colunas, nấo difere entre si pelo teste de

Tukey a $5 \%$ de probabilidade.
Médias seguidas pela mesma letra, nas linhas, não difere entre si pelo teste de Tukey a $5 \%$ de probabilidade.

Neste estudo, os resultados obtidos para a perda de massa fresca, apresentados na Tabela 1, mostram que ocorreu diferença significativa em função dos tratamentos e do período de armazenamento, permitindo concluir que os frutos acondicionados em bandejas de polietileno tereftalato, revestidas externamente com filme plástico de PVC, esticável e auto-aderente de 12 ou $20 \mu \mathrm{m}$, independente da associação ou não com baixa temperatura, apresentaram redução na perda de massa fresca.

Através dos dados da Tabela 1 , verifica-se que os frutos acondicionados e revestidos com filme plástico e armazenados a $11 \pm 1^{\circ} \mathrm{C}$, tiveram vida-útil de 6 dias, enquanto que, em condições de ambiente a vida-útil foi de 3 dias, o que mostra que o uso de filmes associados à baixa temperatura foi eficaz no aumento do tempo de armazenamento dos frutos. Os frutos acondicio- nados e não recobertos, armazenados a $11 \pm 1^{\circ} \mathrm{C}$ tiveram vida-útil de quatro dias, isto é, dois dias a mais do que o tempo observado à temperatura ambiente (Tabela 1), mostrando a eficácia do uso de baixa temperatura no prolongamento da vida-útil dos frutos. O comportamento observado neste estudo é coerente com o preconizado por FABER [12] de que o uso de filmes pode aumentar a vida-útil de frutos de 50 a 400\%. Este fator é importante em jabuticabas que por não amadurecerem após a colheita devem ser colhidas maduras.

Os teores de acidez total titulável dos frutos (dados não mostrados) nos diferentes tratamentos, variaram de 0,75 a $1,18 \mathrm{~g}$ de ácido cítrico por $100 \mathrm{~g}$ de polpa, durante o armazenamento refrigerado e de 0,14 a $1,16 \mathrm{~g}$ de ácido cítrico por $100 \mathrm{~g}$ de polpa, durante o armazenamento em condições ambiente, o que ocasionou acentuada oscilação na relação SST/ATT no decorrer do período de armazenamento, evidenciando que houve retenção no metabolismo de transformação de ácido orgânico (Tabela 2). Este comportamento não condiz com o preconizado por HULME [13] e CHITARRA \& CHITARRA [6], de que após a colheita os teores de ácidos orgânicos diminuem. Por outro lado, os frutos acondicionados em bandejas de poliestireno expandido, revestidos externamente com filme plástico de PVC, esticável e auto-aderente de $12 \mu \mathrm{m}$ (BI1), durante o armazenamento refrigerado apresentaram diminuição acentuada na acidez ao longo do período de armazenamento, provavelmente devido ao processo de senescência, comportamento este condizente com a afirmação de HULME [13] e CHITARRA \& CHITARRA [6], enquanto que os teores de acidez total titulável dos frutos acondicionados não revestidos com filmes plásticos, ao final do período de armazenamento, aumentaram significativamente, em ambas condições de armazenamento.

Os teores de sólidos solúveis totais dos frutos são importantes tanto para o consumo in natura como para a indústria. Os resultados médios obtidos neste estudo, variaram de 12,0 a $15,5^{\circ}$ Brix (dados não mostra-

TABELA 2. Relação sólidos solúveis totais e acidez total titulável (SST/ATT) em jabuticabas 'sabará', durante o armazenamento a baixa temperatura e em condições ambiente. Safra 2001 (Média de 5 repetições)

\begin{tabular}{|c|c|c|c|c|c|c|c|}
\hline \multirow{3}{*}{ Tratamentos } & \multicolumn{7}{|c|}{ Tempo de armazenamento em dias } \\
\hline & & \multicolumn{3}{|c|}{ Em condições ambiente } & \multicolumn{3}{|c|}{ Refrigerado } \\
\hline & 0 & 1 & 2 & 3 & 2 & 4 & 6 \\
\hline $\begin{array}{l}\text { Bandeja tereftalato sem revestimento } \\
\text { com filme plástico }\end{array}$ & $14,66 \mathrm{aA}$ & $12,56 \mathrm{dC}$ & $13,82 \mathrm{~dB}$ & & $12,25 \mathrm{eB}$ & $11,92 \mathrm{eC}$ & \\
\hline $\begin{array}{l}\text { Bandejas de polietileno tereftalato, } \\
\text { revestidas com }\end{array}$ & & & & & & & \\
\hline Filme plásticode $12 \mu \mathrm{m}$ (BP1) & $14,66 \mathrm{aA}$ & $11,78 \mathrm{cD}$ & $12,92 b C$ & $14,05 \mathrm{bB}$ & $12,57 \mathrm{dC}$ & $12,16 \mathrm{dD}$ & $17,23 a A$ \\
\hline Filme plástico de $20 \mu \mathrm{m}$ (BP2) & $14,66 \mathrm{aD}$ & $18,79 b C$ & $19,04 \mathrm{cB}$ & $19,28 \mathrm{cA}$ & $18,68 \mathrm{baA}$ & $16,55 \mathrm{baB}$ & $15,22 b C$ \\
\hline \multicolumn{8}{|l|}{$\begin{array}{l}\text { Bandejas de poliestireno expandido, } \\
\text { revestidas com }\end{array}$} \\
\hline Filme plástico de $12 \mu \mathrm{m}$ (BI1) & $14,66 \mathrm{aC}$ & $14,27 e \mathrm{D}$ & $14,96 \mathrm{eB}$ & $15,65 d A$ & $12,97 \mathrm{cD}$ & $13,17 \mathrm{cC}$ & $14,42 \mathrm{cB}$ \\
\hline Filme plástico de 20um (BI2) & $14,66 \mathrm{aC}$ & $14,42 \mathrm{aD}$ & $14,71 \mathrm{aA}$ & $15,01 \mathrm{aB}$ & $13,79 b B$ & $13,68 b C$ & $12,39 d D$ \\
\hline c.v..$^{(1)}$ & 0,00 & 0,32 & 0,20 & 0,22 & 0,37 & 0,14 & 0,15 \\
\hline
\end{tabular}

(1) $\mathrm{cv}=$ coeficiente de variação em porcentagem.

Médias seguidas pela mesma letra, nas colunas, não difere entre si pelo teste de Tukey a $5 \%$ de probabilidade.

Médias seguidas pela mesma letra, nas linhas, não difere entre si pelo teste de Tukey a $5 \%$ de probabilidade. 
dos), portanto com ligeiro aumento, com exceção dos valores encontrados nos frutos do tratamento BI2 (frutos acondicionados em bandejas de poliestireno expandido, revestidas externamente com filme plástico de PVC, esticável e autoaderente, com 20 micras de espessura) que apresentaram declínio durante o período de armazenamento sob refrigeração do $4 \div$ ao $6 \circ$ dia, de 13,6 a $12,0^{\circ}$ Brix, diminuição esta que pode ser atribuída à transformação do amido em açúcares e às condições da atmosfera no interior da embalagem, conforme preconizado por ZAGORY \& KADER [23].

A relação sólidos solúveis totais e acidez total titulável (SST/STT) são consideradas como um critério de avaliação do 'flavor' em frutos [6], além de ser indicativa do nível de amadurecimento. Os dados da Tabela 2, permitem verificar diferença significativa na relação entre os frutos acondicionados revestidos ou não com filmes plásticos, e que o uso de filmes plásticos influenciou esta característica, elevando a relação, com exceção dos valores obtidos para os frutos do tratamento BI2. Esse aumento deve-se em maior parte à diminuição da acidez total titulável durante o armazenamento.

$\mathrm{O}$ pH é um fator intrínseco ao produto [18], e os valores encontrados para o $\mathrm{pH}$ entre os frutos dos diferentes tratamentos (dados não mostrados) mostram que não houve diferença acentuada, e que ao final do período de armazenamento os frutos dos tratamentos BP2 e BI2, armazenados em condições ambiente mostraram ligeira diminuição da acidez provavelmente devido ao início dos processos de senescência. Os valores de $\mathrm{pH}$ da polpa variaram de 3,5 a 3,8 durante armazenamento em condições de ambiente e de 3,3 a 3,65 durante o armazenamento a $8 \pm 1^{\circ} \mathrm{C}$.

As frutas constituem-se em uma das mais ricas fontes de vitaminas e minerais, onde destaca-se a vitamina C. Como importante fator na nutrição humana, esta substância redutora, é facilmente oxidada quando exposta ao calor, luz e oxigênio, podendo também ser perdida durante o manuseio dos produtos, sendo relativamente estável em meio ácido [5, 6, 16]. Neste estudo, os teores de vitamina $\mathrm{C}$, expresso em mg de acido ascórbico. $100 \mathrm{~g}^{-1}$ de polpa, variaram em função do tempo de armazenamento e do tratamento utilizado (Tabela 3) e a velocidade de redução nos teores de vitamina $\mathrm{C}$ foi maior nos frutos armazenados à temperatura ambiente. Este comportamento é coerente ao observado por JERONIMO \& KANESIRO [15] em mangas. Os frutos acondicionados, ao final do período de armazenamento em ambas temperaturas (Tabela 3), apresentaram maior redução nos teores de vitamina $\mathrm{C}$ em relação ao valor encontrado nos frutos do grupo controle (SE).

Os teores médios de carboidratos solúveis, expresso em mg de glicose. $100 \mathrm{~g}^{-1}$ de polpa dos frutos tiveram uma evolução progressiva (Tabela 4). Em condições de refrigeração, os frutos acondicionados com filmes plásticos foram os que apresentaram os maiores valores. Observa-se ainda que não ocorreram diferenças acentuadas quanto à evolução dos teores de carboidratos solúveis nos diferentes tratamentos avaliados, comportamento este condizente com o preconizado por CHITARRA \& CHITARRA[6] e HULME [13]. Pelos resultados da Tabela 4, pode-se verificar que o aumento dos teores de carboidratos solúveis manteve o mesmo comportamento que o de sólidos solúveis totais, portanto, os carboidratos solúveis devem ser os maiores componentes dos carboidratos solúveis totais. O uso de embalagem modificou esta característica, provavelmente devido à alteração na atmosfera interna das mesmas.

A aparência externa é fundamental em frutos destinados ao mercado in natura, por ser fator de atratividade e exercer influência direta sobre a escolha do consumidor [15, 23] e através dos dados obtidos neste estudo (não mostrados) onde a nota 3,0 foi associada à aparência regular e aceitável para o consumo, pode-se inferir que os frutos acondicionados e recobertos, com filmes plásticos, independentes da espessura utilizada, apresentaram aspecto aceitável para o consumo até ao $3^{\circ}$ dia de armazenamento em condições de ambiente, e até ao $6^{\circ}$ dia de armazenamento sob refrigeração, não se destacando nenhum tratamento.

TABELA 3. Vitamina C, expressa em g. de ácido ascórbico por $100 \mathrm{~g}$ de polpa, em jabuticabas 'sabará', durante o armazenamento a baixa temperatura e em condições ambiente. Safra 2001 (Média de 5 repetições)

\begin{tabular}{|c|c|c|c|c|c|c|c|}
\hline \multirow{3}{*}{ Tratamentos } & \multirow[b]{3}{*}{0} & \multicolumn{6}{|c|}{ Tempo de armazenamento em dias } \\
\hline & & \multicolumn{3}{|c|}{ Em condições ambiente } & \multicolumn{3}{|c|}{ Refrigerado } \\
\hline & & 1 & 2 & 3 & 2 & 4 & 6 \\
\hline $\begin{array}{l}\text { Bandeja tereftalato sem revestimento } \\
\text { com filme plástico }\end{array}$ & $13,30 \mathrm{aB}$ & $14,59 \mathrm{dA}$ & $11,51 \mathrm{dC}$ & & $15,27 \mathrm{cA}$ & $13,33 \mathrm{eB}$ & \\
\hline \multicolumn{8}{|l|}{$\begin{array}{l}\text { Bandejas de polietileno tereftalato, } \\
\text { revestidas com }\end{array}$} \\
\hline Filme plásticode $12 \mu \mathrm{m}$ (BP1) & $13,30 \mathrm{aB}$ & $18,92 a A$ & $13,29 a C$ & $7,65 \mathrm{cD}$ & $15,68 \mathrm{bA}$ & $14,14 \mathrm{~dB}$ & $11,96 \mathrm{aD}$ \\
\hline Filme plástico de 20um (BP2) & $13,30 \mathrm{aB}$ & $14,49 \mathrm{eA}$ & $11,93 \mathrm{cC}$ & $9,367 \mathrm{D}$ & $13,96 \mathrm{eB}$ & $14,43 c \mathrm{~A}$ & $9,08 \mathrm{cD}$ \\
\hline \multicolumn{8}{|l|}{$\begin{array}{l}\text { Bandejas de poliestireno expandido, } \\
\text { revestidas com }\end{array}$} \\
\hline Filme plástico de $12 \mu \mathrm{m}(\mathrm{BI} 1)$ & $13,30 \mathrm{aB}$ & $16,85 \mathrm{bA}$ & $13,13 b \mathrm{~b}$ & $9,42 \mathrm{aD}$ & $14,33 \mathrm{~dB}$ & $16,58 \mathrm{bA}$ & $9,78 \mathrm{bD}$ \\
\hline Filme plástico de $20 \mu \mathrm{m}(\mathrm{BI} 2)$ & $13,30 \mathrm{aB}$ & $15,59 \mathrm{cA}$ & $10,70 \mathrm{eC}$ & $5,81 \mathrm{dD}$ & $16,96 \mathrm{aB}$ & $17,59 a \mathrm{~A}$ & $7,54 \mathrm{dD}$ \\
\hline c.v. ${ }^{(1)}$ & 0,00 & 0,05 & 0,07 & 0,09 & 0,05 & 0,05 & 1,10 \\
\hline
\end{tabular}


TABELA 4. Carboidratos solúveis, expresso em g. de glicose por $100 \mathrm{~g}$ de polpa, em jabuticabas 'sabará, durante o armazenamento a baixa temperatura e em condições ambiente. Safra 2001 (Média de 5 repetições)

\begin{tabular}{|c|c|c|c|c|c|c|c|}
\hline \multirow{3}{*}{ Tratamentos } & & \multicolumn{6}{|c|}{ Tempo de armazenamento em dias } \\
\hline & \multirow[b]{2}{*}{0} & \multicolumn{3}{|c|}{ Em condições ambiente } & \multicolumn{3}{|c|}{ Refrigerado } \\
\hline & & 1 & 2 & 3 & 2 & 4 & 6 \\
\hline $\begin{array}{l}\text { Bandeja tereftalato sem revestimento } \\
\text { com filme plástico }\end{array}$ & $2,66 a C$ & $14,59 \mathrm{dA}$ & $11,51 \mathrm{dC}$ & & $4,93 \mathrm{eB}$ & $5,82 \mathrm{eA}$ & \\
\hline \multicolumn{8}{|l|}{$\begin{array}{l}\text { Bandejas de polietileno tereftalato, } \\
\text { revestidas com }\end{array}$} \\
\hline Filme plásticode $12 \mu \mathrm{m}$ (BP1) & $2,66 a \mathrm{D}$ & $18,92 \mathrm{aA}$ & $13,29 \mathrm{aC}$ & $7,65 \mathrm{cD}$ & $5,89 b C$ & $5,94 \mathrm{~dB}$ & $6,49 \mathrm{dA}$ \\
\hline \multicolumn{8}{|l|}{$\begin{array}{l}\text { Bandejas de poliestireno expandido, } \\
\text { revestidas com }\end{array}$} \\
\hline Filme plástico de $12 \mu \mathrm{m}$ (BI1) & $2,66 \mathrm{aD}$ & $16,85 \mathrm{bA}$ & $13,13 b C$ & $9,42 \mathrm{aD}$ & $6,12 \mathrm{aC}$ & $6,67 \mathrm{bB}$ & $6,85 \mathrm{cA}$ \\
\hline Filme plástico de $20 \mu \mathrm{m}$ (BI2) & $2,66 \mathrm{aD}$ & $15,59 \mathrm{cA}$ & $10,70 \mathrm{eC}$ & $5,81 \mathrm{dD}$ & $5,80 \mathrm{cC}$ & $6,24 c B$ & $7,17 \mathrm{bA}$ \\
\hline c.v. ${ }^{(1)}$ & 0,00 & 0,05 & 0,05 & 0,04 & 0,07 & 0,05 & 1,10 \\
\hline
\end{tabular}

(1) $\mathrm{cv}=$ coeficiente de variação em porcentagem.

Médias seguidas pela mesma letra, nas colunas, não difere entre si pelo teste de Tukey a $5 \%$ de probabilidade.

Médias seguidas pela mesma letra, nas linhas, não difere entre si pelo teste de Tukey a $5 \%$ de probabilidade.

A textura é considerada um dos atributos de importância na qualidade de frutos, já que afeta a sua resistência ao transporte, às técnicas de conservação pós-colheita e ataque de microrganismos. Pelos dados observados nesse estudo (não mostrados) infere-se que a textura sofreu alteração a partir do primeiro dia de armazenamento em condições ambiente e que os frutos acondicionados em bandejas de poliestireno expandido, revestidas externamente com filme plástico de

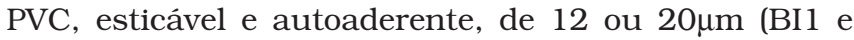
$\mathrm{BI} 2$, foram os que apresentaram a maior perda de textura, provavelmente, devido à perda de umidade, através da transpiração do frutos, que ocasionou murchamento e enrugamento da casca, tornando difícil a pressão pela boca.
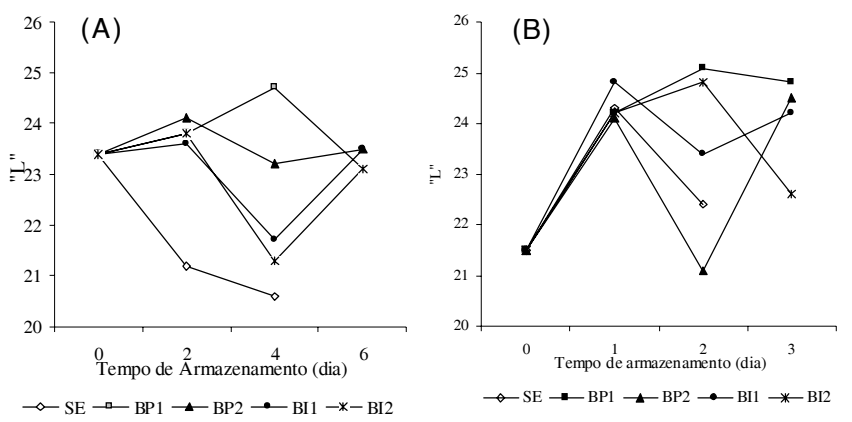

FIGURA 1. Evolução da coloração da casca, expressa em 'L', em jabuticabas 'sabará, durante o armazenamento em condições ambiente(A) e a baixa temperatura (B).

As medidas de coloração da casca de jabuticabas acondicionadas em bandejas revestidas ou não com filmes plásticos, foram expressas através do sistema Hunter e estão apresentadas nas Figuras 1 e 2. No decorrer do estudo observou-se que ocorreu variação no valor da luminosidade (L), fato este que pode ser atribuído à perda de umidade pelos frutos através do processo de transpiração, à perda da coloração preta-roxa brilhante, tornando-se opacos, principalmente, nos frutos não recobertos.
Os valores de Hue (b/a) é uma medida apropriada para expressar a variação da coloração em produtos vegetais, e é um parâmetro que pode ser utilizado para identificar ponto de colheita. Os valores obtidos neste estudo demonstram que os tratamentos não interferiram na intensidade da coloração da casca das jabuticabas (Figura 2), fato este importante, tendo em vista que a coloração roxa intensa ou preta é um dos parâmetros de qualidade dessa fruta e de procura pelo consumidor.
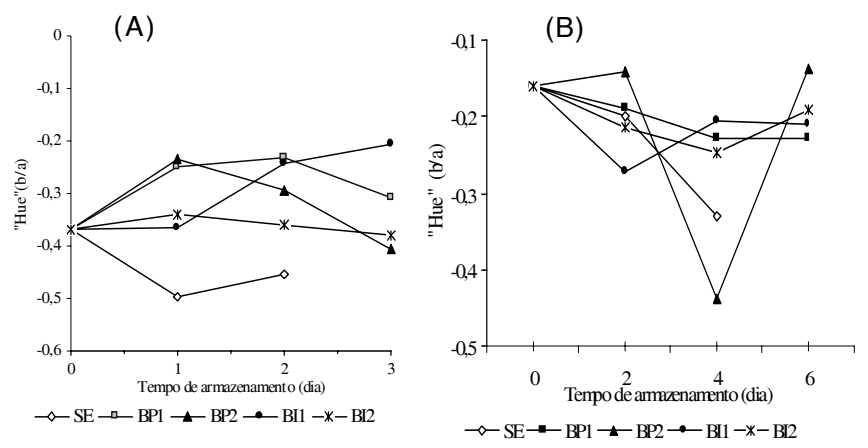

FIGURA 2. Evolução da coloração da casca, expressa em 'Hue' em jabuticabas 'sabará, durante o armazenamento em condições ambiente (A) e a baixa temperatura (B).

\section{4 - CONCLUSÕES}

Considerando-se os resultados obtidos pode-se concluir que os frutos acondicionados em bandejas revestidas ou não com filmes plásticos e armazenados sob refrigeração e em condições ambiente, apesar de terem resistido por até 4 e 2 dias, respectivamente, não apresentaram aparência recomendável para comercialização ao final do período de armazenamento, devido ao enrugamento da casca. O uso de filmes plásticos, associados ou não a baixa temperatura, reduziu a perda de massa fresca, manteve a aparência geral dos frutos e não interferiu na evolução dos teores de acidez total titulável, sólidos solúveis totais, e pH, mas 
interferiou na evolução dos carboidratos solúveis e vitamina $\mathrm{C}$ durante o período de armazenamento.

\section{5 - REFERÊNCIAS BIBLIOGRÁFICAS}

[1] AOAC- Association of Official Analystical Chemists. Official methods os analyss of the association of official analystical chemists. $13^{\mathrm{a}}$ ed. Washington: AOAC, 1980, cap. 22, p.359-734. Fruits and fruits products.

[2] AWAD, M. Fisiologia pós-colheita de frutos. 1.ed. São Paulo, Nobel, 1993, 114p.

[3] BANZATTO, D.A.; KRONKA, S.N. de. Experimentação Agrícola. 3.ed. Jaboticabal: FUNEP, 1995, 247p.

[4] BIBLIE, R.B., SHINGA, S. Canopy position influences CIELAB coordinates of peach color. HortScience, Alexandria, v. 28, n. 10, p. 992-993, 1993.

[5] CAMBRAIA, J.; CASALI, V.W.D.; COUTO, F.A.A. Vitamina $\mathrm{C}$ em pimentas e pimentões. Revista Ceres, Belo Horizonte, v. 18, p. 177-194, 1971.

[6] ChitarRa, M.I.F.; ChitarRA, A.B. Pós-colheita de frutos e hortaliças: fisiologia e manuseio. Lavras: ESAL/FAEPE, 1990. 320p.

[7] COELHO, A.H.R. Qualidade pós-colheita de pêssegos. Informe Agropecuário, Belo Horizonte, MG, v. 17, n. 180, p. 31-38, 1994.

[8] DONADIO, L.C. Jabuticaba (Myrciaria jaboticaba (Vell.) Berg). Jaboticabal: FUNEP, 2000, 55 p.

[9] DONADIO, L.C. Noções práticas de fruticultura. Campinas: Fundação Cargill, 1993, 74p.

[10] DUARTE, O.; LUDDERS, P.; HUETE, M. Extending storage life of jaboticaba (Myrciaria cauliflora Berg) fruits. 14 Congresso Brasileiro de Fruticultura, 1996, Curitiba, PR, Resumos..., Curitiba-PR:SBF, p. 556, 1996.

[11] DUBOIS, M.; GILLEWS, K.A.; HAMILTON, J.K.; REBER, P.A.; SMITH, F. Colorimetric method for determination of sugar and related substances. Analytical. Chemistry, Washington, v. 28, n. 3, p. 350-356, 1956.

[12] FARBER, J.M. Microbiological aspects of modified atmosphere packing technology- a review. Journal of Food Protection, v. 54, n. 1, p. 58-70, 1991.

[13] Hulme, A.C. The mango. In: HULME, A.C.(ed) The biochemistry of fruits and their products. New York and London: Academic Press, v.2, p.233-254, 1971.

[14] I.A.L. Normas Analíticas: método químico e físico para análise de alimentos. 2.ed. São Paulo, SP, 1985, v. 1, 371p.
[15] JERONIMO, E.M.; KANESIRO, M.A.B. Efeito da associação de armazenamento sob refrigeração e atmosfera modificada na qualidade de mangas 'Palmer'. Revista Brasileira de Fruticultura, Jaboticabal-SP, v. 22, n. 2, p.237-243, 2000.

[16] KADER, A.A. Postharvest Tecnology of Horticultultural Crops. Publication 3311, University of California, Division of Agriculture and Natural Resources, Oakland CA, 1992. 296p.

[17] KOSHI, D.V. Is current modified / controlled atmosphere packaging technology applicate to U.S. food market Food Technology, Chicago, v. 28, n. 9, p. 50-60, 1988.

[18] LEITÃO, M.F.F. Microbiologia de sucos, polpas e produtos ácidos. Manual Técnico, Campinas, n. 8, p. 32-52, 1991.

[19] MAGAlHÃES, M.M.; BARROS, R.S.; FINGER, F.L. Changes in structural carbohydrates in developing fruit of Myrciaria jabuticaba. Scientia Horticulturae, Netherlands, v. 66, n. 66, p. 17-22, 1996.

[20] MATTOS, J.R. Frutíferas nativas do Brasil: jaboticabeiras. Porto Alegre, 1983, 92p.

[21] TRESSLER, D.K.; JOSYLIN, M.A. Fruits and vegetables juice processing technology. Westport: Conn: The AVI. 1961, 1028p.

[22] WILLS, R.B.H.; LEE, T.H.; GRAHAM, D.; McGLASSON, W.B.; HALI, E.G. Post harvest- An Introduction to the physiology and handling of fruit and vegetables. Kensington, New South Wales University Press. 1982, $166 \mathrm{p}$.

[23] ZAGORY, D.; KADER, A.A. Quality maintance in fresh fruits and vegetables by controlled atmospheres. In: JEN, J.J. Quality factors of fruits and vegetable: chemistry and technology. Washington: American Chemical Society, 1989. Cap. 14, p. 174-178

[24] ZAMBRANO, J.; BRICEÑO, C.; MENDES, E.C. Repuesta de los frutos de mango al permanganato de potasio como absorbente del etileno durante el almacenamiento. 14 Congresso Brasileiro de Fruticultura, Curitiba, PR, Resumos..., Curitiba: Sociedade Brasileira de Fruticultura, p. 480, 1996.

\section{6 - AGRADECIMENTOS}

À Fundação de Amparo à Pesquisa do Estado de São Paulo - FAPESP, pela Bolsa de Iniciação Científica ao terceiro e quarto autores, e pelo auxílio financeiro. 